Article

\title{
Chitosan Oligosaccharides Protect Sprague Dawley Rats from Cyclic Heat Stress by Attenuation of Oxidative and Inflammation Stress
}

\author{
Ruixia Lan, Siqi Li, Qingqing Chang and Zhihui Zhao* \\ Department of Animal Science, College of Agriculture, Guangdong Ocean University, NO.1 Haida Road, \\ Mazhang Distinct, Zhanjiang 524-088, China; Lanrx@gdou.edu.cn (R.L.); Lsq_i@outlook.com (S.L.); \\ changqingqing@outlook.com (Q.C.) \\ * Correspondence: zhzhao@jlu.edu.cn; Tel.: +86-135-7875-4340; Fax: +86-0759-238-3440
}

Received: 2 November 2019; Accepted: 29 November 2019; Published: 3 December 2019

Simple Summary: Heat stress has negative effects on animal health and performance, and chitosan oligosaccharides (COS) exhibits antioxidant and anti-inflammatory properties. The aim of this study was to evaluate the effects of COS alleviation of oxidative stress and inflammatory response in heat-stressed rats. The results indicated heat stress decreased $(p<0.05)$ growth performance; the relative weight of spleen and kidney; and the level of antioxidant enzymes and IL-10 in liver, spleen, and kidney, while it increased $(p<0.05)$ the MDA and inflammatory cytokines concentration. Dietary COS supplementation enhanced $(p<0.05)$ ADG, the relative weight of spleen and kidney, and the level of antioxidant enzymes and IL-10 in liver, spleen, and kidney. Collectively, COS was beneficial to heat-stressed rats by alleviating oxidative damage and inflammatory response.

\begin{abstract}
Chitosan oligosaccharides (COS) exhibits antioxidant and anti-inflammatory properties. The aim of this study was to evaluate the effects of COS on antioxidant system and inflammatory response in heat-stressed rats. A total of 30 male rats were randomly divided to three groups and reared at either $24^{\circ} \mathrm{C}$ or $35^{\circ} \mathrm{C}$ for $4 \mathrm{~h} / \mathrm{d}$ for this 7-day experiment: CON, control group with basal diet; HS, heat stress group with basal diet; HSC, heat stress with $200 \mathrm{mg} / \mathrm{kg}$ COS supplementation. Compared with the CON group, HS significantly decreased $(p<0.05)$ average daily gain (ADG); average daily feed intake (ADFI); the relative weight of spleen and kidney; the level of liver CAT, GSH-Px, T-AOC, and IL-10; spleen SOD, GSH-Px, GSH, and IL-10; and kidney SOD, GSH-Px, T-AOC, and IL-10, while significantly increased the MDA concentration in liver, spleen, and kidney; the liver IL-1 $\beta$ concentration; and spleen and kidney IL- 6 and TNF- $\alpha$ concentration. In addition, dietary COS supplementation significantly improved $(p<0.05)$ ADG; the relative weight of spleen and kidney; the level of liver GSH-Px, spleen GSH-Px, GSH, and IL-10; and kidney GSH-Px, while significantly decreased $(p<0.05)$ liver IL-1 $\beta$ concentration under heat stress condition. Collectively, COS was beneficial to heat-stressed rats by alleviating oxidative damage and inflammatory response.
\end{abstract}

Keywords: chitosan oligosaccharides; heat stress; antioxidant; anti-inflammatory; Sprague Dawley rats

\section{Introduction}

High ambient temperature has negative effects on animal and human health and performance and is responsible for billions of dollars losses to global animal agriculture [1]. Consequently, from a human medicine and agriculture perspectives, researches focusing on the identification and implementation of strategies to improve welfare and performance are essential [2]. Numerous studies have demonstrated that heat stress can induce multiple physiological disturbances, including endocrine disorders $[3,4]$, 
electrolyte imbalance [5], immune dysfunction [6-8], and oxidative stress [9-11]. The heat stress response pathway is partly attributed to the increase of pro-inflammatory cytokines and reactive oxygen species (ROS) production [12-14]. The increased ROS resulted in stimulated intracellular and extracellular superoxide formation and was responsible for oxidative stress [15]. Heat stress generates ROS, which may modulate the inflammatory transcription factor nuclear factor- $\mathrm{kB}$ [16], inducing hormonal and metabolic changes, secretion of inflammatory cytokines [17], and decrease the level of antioxidant enzymes [17]. Former studies demonstrated that the pro-inflammatory cytokines level will increase under heat stress $[13,14,18]$. In addition, both cytokines and ROS are inflammatory mediators; there is interactive association between oxidative stress and the release of inflammatory cytokines $[19,20]$. To date, nutritional interventions are widely used to diminish the negative effects of heat stress $[2,14,21]$.

Chitosan oligosaccharides (COS) are the degraded products of chitosan or chitin [22], which is well-known for being soluble in water and less viscous [23], biocompatible [24], non-toxic [25], and mucoadhesive [26]. Innumerable studies have demonstrated that COS exhibits various biology activities including antioxidant [27,28], anti-inflammatory [29-31], anti-bacterial [32,33], anti-fungal [34], anti-tumor [35], anti-obesity [36], anti-diabetic [37], calcium absorption enhancing [38], and immune ability enhancing [31,39]. Recent studies also indicated that COS could be used as therapeutic agents in inflammation, suppressing the production of nitric oxide, prostaglandin $E_{2}$, and pro-inflammatory cytokines [39-41]. Furthermore, it has been demonstrated that COS can prevent mice from lipopolysaccharide (LPS) challenge by virtue of anti-inflammatory effects as well as antioxidant properties [42]. However, relative few studies were conducted to evaluate the effects of COS on the inflammatory response and antioxidant capacities under heat stress condition. Therefore, the aim of this study to evaluate the effects of COS under cycle heat stress on inflammatory response and antioxidant capacities in Sprague Dawley (SD) rats.

\section{Materials and Methods}

\subsection{Animal Ethics}

The experimental protocol used in the present study was approved by the Animal Care and Use Committee of Guangdong Ocean University, China (SYXK-2018-0147).

\subsection{Chemicals and Reagents}

COS was purchased from Jiangsu Xinrui Biotechnology Co., Ltd. (HPLC purity 95\%, deacetylation degree over $95 \%$ and average molecular weight below $32 \mathrm{kDa}$ ). The commercial kits used for the determination of enzymes activities of superoxide dismutase (SOD), catalase (CAT), glutathione peroxidase (GSH-Px), glutathione (GSH), and total antioxidant capacity (T-AOC), the content of malondialdehyde (MDA), enzyme-linked immunosorbent assay (ELISA) kits of interleukin-1 $\beta$ (IL-1 $\beta$ ), interleukin-6 (IL-6), interleukin-10 (IL-10), and tumor necrosis factor- $\alpha$ (TNF- $\alpha$ ), as well as BCA protein assay kit were purchased from Nanjing Jiancheng Bioengineering Institute (Jiangsu, China). Other chemicals used were analytical grade and purchased from Shanghai chemical agents' company, China.

\subsection{Animals, Experiment Design, and Diets}

The 30 male Sprague Dawley rats (6-8 weeks, $119.65 \pm 3.93 \mathrm{~g})$ used in this study were obtained from Beijing Administration Office of Laboratory Animal (Beijing, China). The rats were individually housed in polycarbonate cages with soft wood granulate floors and kept at $24^{\circ} \mathrm{C}$, with a $12 \mathrm{~h}$ light-dark cycle. After a week of acclimatization, 30 rats were randomly divided into one of three groups with 10 rats in each group for this 7-day experiment: (1) CON, control group with basal diet; (2) HS, heat stress group with basal diet; (3) HSC, heat stress with $200 \mathrm{mg} / \mathrm{kg}$ COS supplementation. The COS supplementation level was according to our former study (data was not shown). All rats had free access to diets and drinking water. The basal diets were formulated to meet the nutritional requirements 
recommendation by American Institute of Nutrition-93 diet [43], the composition listed in Table 1. To induce heat stress, the rats in HS and HSC groups were exposed to cyclical heat stress conditions ( $35^{\circ} \mathrm{C}$ from 08:00 to 12:00 and $24^{\circ} \mathrm{C}$ from 12:00 to 08:00), while the CON group was maintained at $24^{\circ} \mathrm{C}$ for $24 \mathrm{~h}$. Body weight, daily water intake, and feed intake were recorded daily.

Table 1. Dietary composition and nutrient content of the basal diet.

\begin{tabular}{cc}
\hline Ingredients, $\mathbf{g} / \mathbf{k g}$ & Basal Diet \\
\hline Cornstarch & 464.0 \\
Casein & 140.0 \\
Dextrinized cornstarch & 155.0 \\
Sucrose & 100.0 \\
Soybean oil & 40.0 \\
Cellulose acetate & 50.0 \\
Mineral permix ${ }^{1}$ & 35.0 \\
Vitamin permix ${ }^{2}$ & 10.0 \\
L-Methionine & 1.8 \\
L-Cystine & 1.8 \\
Choline bitartrate & 2.4 \\
Tert-butylhydroquinone & 0.01 \\
Gross energy (MJ/kg) & 16.22
\end{tabular}

1 Mineral mixture was prepared as AIN-93 (mg/kg of mixture): $\mathrm{CaCO}_{3}, 3.70 \times 10^{5} ; \mathrm{KH}_{2} \mathrm{PO}_{4}, 1.96 \times 10^{5}$; $\mathrm{K}_{3} \mathrm{C}_{6} \mathrm{H}_{5} \mathrm{O}_{7} \cdot \mathrm{H}_{2} \mathrm{O}, 7.08 \times 10^{4} ; \mathrm{NaCl}, 7.4 \times 10^{4} ; \mathrm{K}_{2} \mathrm{SO}_{4}, 4.66 \times 10^{4} ; \mathrm{MgO}, 2.4 \times 10^{4} ; \mathrm{FeC}_{6} \mathrm{H}_{5} \mathrm{O}_{7} \mathrm{H}_{2} \mathrm{O}, 6.06 \times 10^{3}$; $\mathrm{ZnCO}_{3}, 1.65 \times 10^{3} ; \mathrm{MnCO}_{3}, 630 ; \mathrm{CuCO}_{3} \mathrm{Cu}(\mathrm{OH})_{2} \mathrm{H}_{2} \mathrm{O}, 324 ; \mathrm{NaSiO}_{3} \cdot 9 \mathrm{H}_{2} \mathrm{O}, 1.45 \times 10^{3} ; \mathrm{CrK}\left(\mathrm{SO}_{4}\right) \cdot 12 \mathrm{H}_{2} \mathrm{O}, 275 ; \mathrm{LiCl}$, 17.4; $\mathrm{H}_{3} \mathrm{BO}_{3}, 81.5 ; \mathrm{NaF}, 63.5 ; \mathrm{NiCO}_{3} \cdot 2 \mathrm{Ni}(\mathrm{OH})_{2} \cdot 4 \mathrm{H}_{2} \mathrm{O}, 30.6 ; \mathrm{NH}_{4} \mathrm{VO}_{3}, 6.6$; sucrose was added to make a total of $1 \mathrm{~kg} .{ }^{2}$ Vitamin mixture was prepared as AIN-93 (mg/kg of mixture): Nicotinic, $3.0 \times 10^{3}$; calcium pantothenate, $1.6 \times 10^{3}$; pyridoxine hydrochloride, 700; thiamine hydrochloride, 600; riboflavin, 600; folic acid, 200; D-biotin, 20; cyanocobalamin, $2.5 \times 10^{3}$; a-tocopherol, $1.5 \times 10^{4}$; cholecalciferol, 250; phylloquinone, 75 ; sucrose was added to make a total of $1 \mathrm{~kg}$.

\subsection{Tissue Collection}

At the end of the experimental, all rats were fasted for $12 \mathrm{~h}$ and 6 rats were randomly selected and euthanized under general anesthesia with diethyl ether. The liver, kidney, and spleen were harvested and weighed, then washed in ice-cold saline solution. All organ weights were expressed as a percentage of live BW $(\mathrm{g} / \mathrm{kg})$, based on the studies by Wu et al. [44]. For biochemical assays, a 10\% homogenate of the tissue was prepared in PBS (0.01M, pH 7.4) and centrifuged at $3000 \times g$ for 10 min at $4{ }^{\circ} \mathrm{C}$, and the supernatant was harvested for further assays.

\subsection{Assay of Antioxidant, Pro-Inflammatory, and Anti-Inflammatory Indices in Plasma and Tissue Samples}

The level of MDA, SOD, CAT, GSH-Px, GSH, T-AOC, IL-1 $\beta$, IL-6, IL-10, and TNF- $\alpha$ in liver, kidney, and spleen were measured according to the manufactures' protocol.

\subsection{Statistical Analysis}

Data were analyzed by one-way ANOVA using the GLM procedures of SAS (V9.1, SAS Inst., Inc., Cary, NC, USA). Data for the CON group versus the HS group or the HS group versus the HSC group were done to compare the effects of heat stress or COS supplementation $y=$ under heat stress. Significant differences between treatment means were determined by using Duncan's multiple range tests, and $p<0.05$ was considered significant.

\section{Results}

\subsection{Apparent Biological Response}

The growth performance and relative organ weight of SD rats are shown in Table 2. There was no significant difference in FCR among treatments. The HS group showed a significant decrease 
$(p=0.0048)$ in ADFI compared with the CON group. The ADG, the relative weight of spleen and kidney, in the HS group was higher $(p<0.05)$ than that in the CON and HSC group.

Table 2. Effects of cycle heat stress or chitosan oligosaccharide supplementation during cyclic heat stress on growth performance and relative organ weights in Sprague Dawley rats.

\begin{tabular}{|c|c|c|c|c|c|}
\hline \multirow{2}{*}{ Item $^{1}$} & \multicolumn{3}{|c|}{ Treatment } & \multicolumn{2}{|c|}{$p$-Value } \\
\hline & $\mathrm{CON}$ & HS & HSC & HS $^{2}$ & $\cos ^{3}$ \\
\hline Final body weight, $g$ & $170.29 \pm 10.32$ & $168.74 \pm 7.55$ & $169.94 \pm 9.15$ & 0.1237 & 0.1431 \\
\hline $\mathrm{ADG}, \mathrm{g}$ & $3.52 \pm 0.38^{a}$ & $2.43 \pm 0.36^{b}$ & $3.02 \pm 0.47^{a}$ & 0.0013 & 0.0360 \\
\hline ADFI, $g$ & $12.49 \pm 1.60^{\mathrm{a}}$ & $10.12 \pm 0.58^{b}$ & $11.19 \pm 1.21^{\mathrm{ab}}$ & 0.0048 & 0.1338 \\
\hline FCR & $3.58 \pm 0.56$ & $4.24 \pm 0.66$ & $3.79 \pm 0.74$ & 0.0640 & 0.1847 \\
\hline Liver $\left(\mathrm{mg} \mathrm{g}^{-1}\right)$ & $48.86 \pm 4.61$ & $43.29 \pm 3.11$ & $50.95 \pm 10.76$ & 0.1909 & 0.0824 \\
\hline Spleen $\left(\mathrm{mg} \mathrm{g}^{-1}\right)$ & $6.27 \pm 1.64^{\mathrm{a}}$ & $4.20 \pm 0.81^{b}$ & $5.48 \pm 1.60^{\mathrm{a}}$ & 0.0007 & 0.0144 \\
\hline Kidney $\left(\mathrm{mg} \mathrm{g}^{-1}\right)$ & $11.29 \pm 2.96^{\mathrm{a}}$ & $7.56 \pm 1.44^{b}$ & $9.88 \pm 2.87^{\mathrm{a}}$ & 0.0008 & 0.0148 \\
\hline
\end{tabular}

The effects of cyclic heat stress on daily water intake are shown in Table 3. The HS group showed a higher $(p<0.05)$ daily water intake than the CON group on days $1,2,3,5,6$, and 7 . There was no significant effect on daily water intake in the HSC group compared with HS group, except a decreasing $(p<0.05)$ on day 6.

Table 3. Effects of cycle heat stress or chitosan oligosaccharide supplementation during cyclic heat stress on daily water intake in Sprague Dawley rats.

\begin{tabular}{cccccc}
\hline \multirow{2}{*}{ Item/g } & \multicolumn{3}{c}{ Treatment $^{\mathbf{1}}$} & \multicolumn{2}{c}{$p$-Value } \\
\cline { 2 - 6 } & CON & HS & HSC & HS $^{\mathbf{2}}$ & COS $^{\mathbf{3}}$ \\
\hline Day 1 & $13.53 \pm 2.31^{\mathrm{b}}$ & $19.34 \pm 3.40^{\mathrm{a}}$ & $18.75 \pm 2.68^{\mathrm{a}}$ & 0.0015 & 0.6681 \\
Day 2 & $18.71 \pm 3.20^{\mathrm{b}}$ & $30.44 \pm 5.35^{\mathrm{a}}$ & $26.77 \pm 3.82^{\mathrm{a}}$ & 0.0002 & 0.0977 \\
Day 3 & $20.68 \pm 3.54^{\mathrm{b}}$ & $25.25 \pm 4.44^{\mathrm{a}}$ & $25.13 \pm 3.58^{\mathrm{a}}$ & 0.0333 & 0.9497 \\
Day 4 & $25.18 \pm 4.31^{\mathrm{a}}$ & $29.58 \pm 5.20$ & $28.97 \pm 4.13$ & 0.0730 & 0.7846 \\
Day 5 & $24.02 \pm 4.11^{\mathrm{a}}$ & $34.94 \pm 6.15^{\mathrm{b}}$ & $39.15 \pm 5.59^{\mathrm{b}}$ & 0.0014 & 0.1227 \\
Day 6 & $23.25 \pm 3.98^{\mathrm{a}}$ & $30.78 \pm 5.41^{\mathrm{b}}$ & $25.51 \pm 3.64^{\mathrm{a}}$ & 0.0056 & 0.0337 \\
Day 7 & $23.64 \pm 4.04^{\mathrm{a}}$ & $32.86 \pm 5.78^{\mathrm{b}}$ & $32.33 \pm 4.61^{\mathrm{b}}$ & 0.0025 & 0.8247 \\
\hline
\end{tabular}

${ }^{1}$ Values are mean \pm standard error, $\mathrm{n}=6$. The values having different superscript letters are different $(p<0.05)$. CON, thermoneutral $\left(24^{\circ} \mathrm{C}\right.$ for $\left.24 \mathrm{~h} / \mathrm{d}\right)$; HS, heat stress $\left(35^{\circ} \mathrm{C}\right.$ for $4 \mathrm{~h} / \mathrm{d}$ followed by $24^{\circ} \mathrm{C}$ for $\left.20 \mathrm{~h} / \mathrm{d}\right)$; HSC, heat stress with $200 \mathrm{mg} / \mathrm{kg}$ COS supplementation. ${ }^{2} \mathrm{CON}$ group vs. HS group. ${ }^{3} \mathrm{HS}$ group vs. HSC group.

\subsection{MDA, Antioxidant Enzymes, GSH, and T-AOC in Liver}

The effects of cyclic heat stress on MDA, antioxidant enzymes, GSH, and T-AOC in liver are shown in Figure 1. No significant difference in the activity of SOD (Figure 1B) and GSH (Figure 1E) among treatments. The HS group showed increase $(p<0.05)$ in the concentration of MDA (Figure 1A), as well as decrease $(p<0.05)$ in the activity of CAT (Figure 1C), GSH-Px (Figure 1D), and T-AOC (Figure 1F) compared with the CON group. 

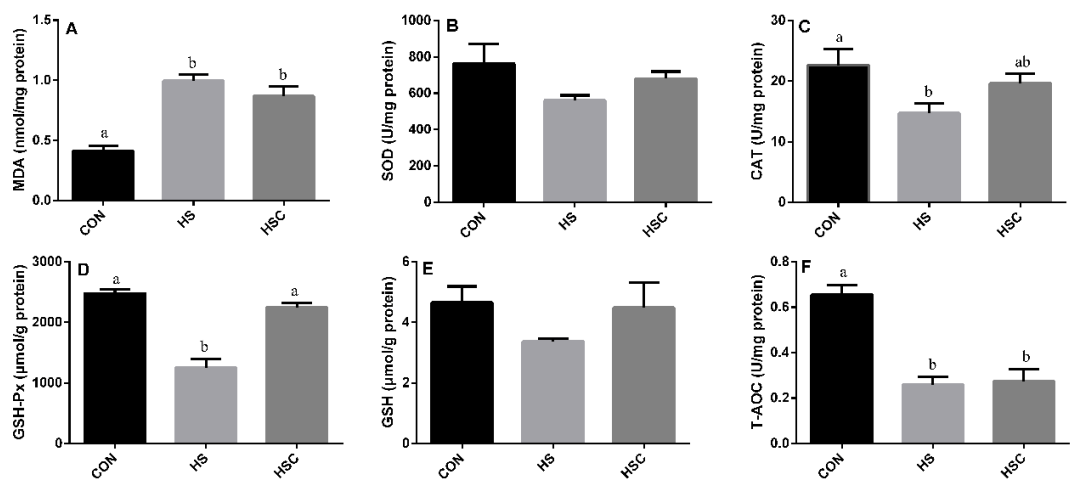

Figure 1. Effects of cycle heat stress or chitosan oligosaccharides (COS) supplementation during cyclic heat stress on MDA, antioxidant enzymes, GSH, and T-AOC in liver. Values are mean \pm standard error, $\mathrm{n}=6$. The values having different superscript letters are different $(p<0.05)$. CON, thermoneutral $\left(24{ }^{\circ} \mathrm{C}\right.$ for $\left.24 \mathrm{~h} / \mathrm{d}\right)$; HS, heat stress $\left(35^{\circ} \mathrm{C}\right.$ for $4 \mathrm{~h} / \mathrm{d}$ followed by $24^{\circ} \mathrm{C}$ for $20 \mathrm{~h} / \mathrm{d}$ ); HSC, heat stress with $200 \mathrm{mg} / \mathrm{kg}$ COS supplementation. MDA, malondialdehyde; SOD, superoxide dismutase; CAT, catalase; GSH-Px, glutathione peroxidase; GSH, glutathione; T-AOC, total antioxidant capacity.

\subsection{MDA, Antioxidant Enzymes, GSH, and T-AOC in Spleen}

The effects of cyclic heat stress or with COS supplementation during heat stress on MDA, antioxidant enzymes, GSH, and T-AOC in spleen are shown in Figure 2. There was no significant difference in the activity of CAT (Figure 2C) and T-AOC (Figure 2F) among treatments. The HS group showed increase $(p<0.05)$ in the level of MDA (Figure 2A), as well as decrease $(p<0.05)$ in the activity of SOD (Figure 2B), GSH-Px (Figure 2D), and GSH (Figure 2E) compared with the CON group. The HSC group showed increase $(p<0.05)$ in the activity of GSH-Px and GSH compared with the HS group.
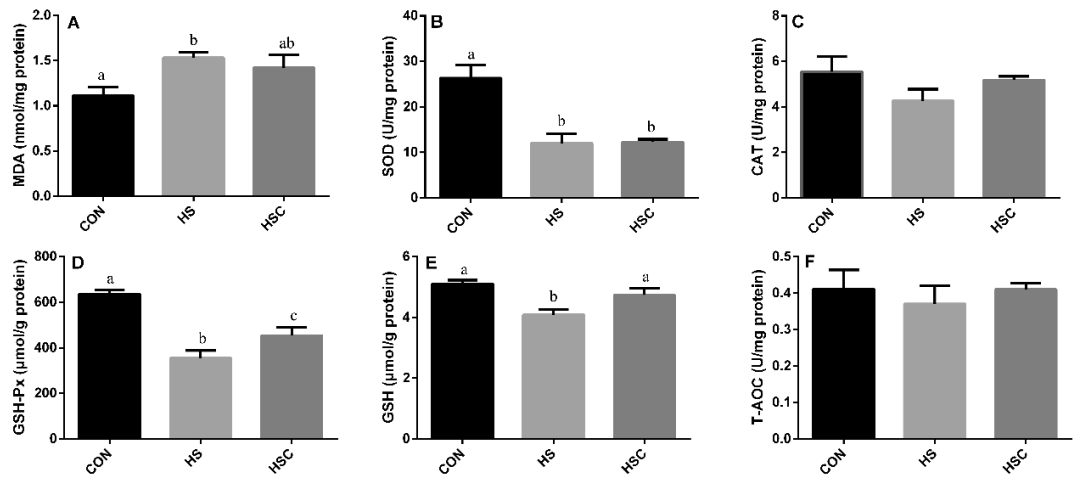

Figure 2. Effects of cycle heat stress or chitosan oligosaccharides (COS) supplementation during cyclic heat stress on MDA, antioxidant enzymes, GSH, and T-AOC in spleen. Values are mean \pm standard error, $\mathrm{n}=6$. The values having different superscript letters are different $(p<0.05)$. CON, thermoneutral $\left(24{ }^{\circ} \mathrm{C}\right.$ for $\left.24 \mathrm{~h} / \mathrm{d}\right)$; HS, heat stress $\left(35^{\circ} \mathrm{C}\right.$ for $4 \mathrm{~h} / \mathrm{d}$ followed by $24{ }^{\circ} \mathrm{C}$ for $\left.20 \mathrm{~h} / \mathrm{d}\right)$; HSC, heat stress with $200 \mathrm{mg} / \mathrm{kg}$ COS supplementation. MDA, malondialdehyde; SOD, superoxide dismutase; CAT, catalase; GSH-Px, glutathione peroxidase; GSH, glutathione; T-AOC, total antioxidant capacity.

\subsection{MDA, Antioxidant Enzymes, GSH, and T-AOC in Kidney}

The effects of cyclic heat stress during heat stress on MDA, antioxidant enzymes, GSH, and T-AOC in kidney are shown in Figure 3. There was no significant difference in the activity of CAT (Figure 3C) and GSH (Figure 3E) among treatments. The HS group showed increase $(p<0.05)$ in the level of MDA (Figure 3A), as well as a significant decrease in the activity of SOD (Figure 3B), GSH-Px (Figure 3D), and T-AOC (Figure 3F) compared with the CON group. The HSC group showed increase $(p<0.05)$ in the activity of GSH-Px compared with the HS group. 

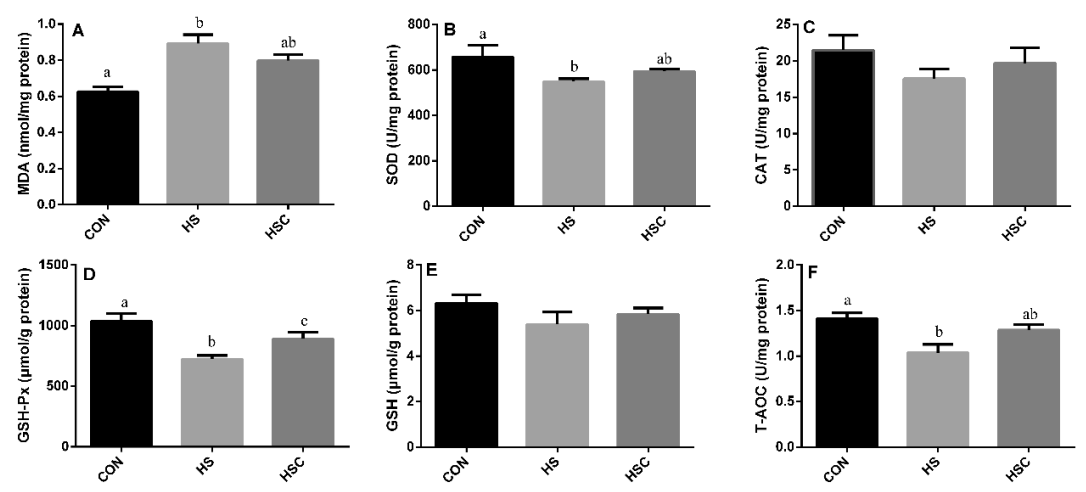

Figure 3. Effects of cycle heat stress or chitosan oligosaccharides (COS) supplementation during cyclic heat stress on MDA, antioxidant enzymes, GSH, and T-AOC in kidney. Values are mean \pm standard error, $\mathrm{n}=6$. The values having different superscript letters are different $(p<0.05)$. CON, thermoneutral $\left(24{ }^{\circ} \mathrm{C}\right.$ for $\left.24 \mathrm{~h} / \mathrm{d}\right)$; HS, heat stress $\left(35^{\circ} \mathrm{C}\right.$ for $4 \mathrm{~h} / \mathrm{d}$ followed by $24^{\circ} \mathrm{C}$ for $20 \mathrm{~h} / \mathrm{d}$ ); HSC, heat stress with $200 \mathrm{mg} / \mathrm{kg}$ COS supplementation. MDA, malondialdehyde; SOD, superoxide dismutase; CAT, catalase; GSH-Px, glutathione peroxidase; GSH, glutathione; T-AOC, total antioxidant capacity.

\subsection{IL-1 $\beta, I L-6, I L-10$, and TNF- $\alpha$ in Liver}

The effects of cyclic heat stress during heat stress on IL-1 $\beta$, IL-6, IL-10, and TNF- $\alpha$ in liver are shown in Figure 4. There was no significant difference in the level of IL-6 (Figure 4B) and TNF- $\alpha$ (Figure 4D) among treatments. The HS group showed increase $(p<0.05)$ in the level of IL-1 $\beta$ (Figure 4A), as well as decrease in the level of IL-10 (Figure 4C), compared with the CON group. The HSC group showed decrease $(p<0.05)$ in the level of IL-1 $\beta$ compared with the HS group.
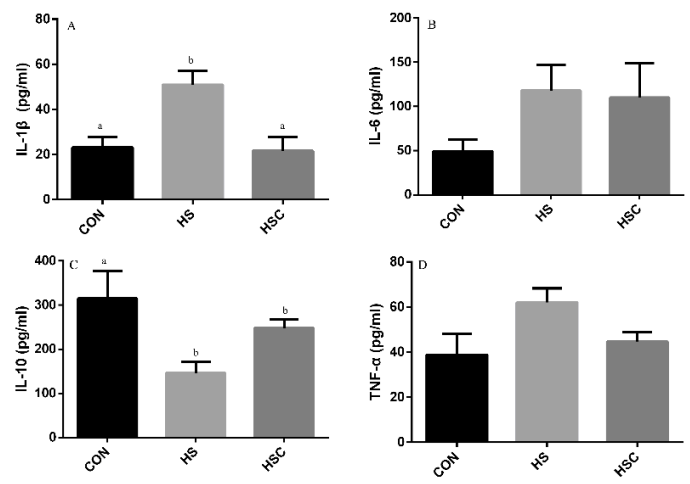

Figure 4. Effects of cycle heat stress or chitosan oligosaccharides (COS) supplementation during cyclic heat stress on IL-1 $\beta$, IL-6, IL-10, and TNF- $\alpha$ in liver. Values are mean \pm standard error, $n=6$. The values having different superscript letters are different $(p<0.05)$. CON, thermoneutral $\left(24^{\circ} \mathrm{C}\right.$ for $\left.24 \mathrm{~h} / \mathrm{d}\right)$; HS, heat stress $\left(35^{\circ} \mathrm{C}\right.$ for $4 \mathrm{~h} / \mathrm{d}$ followed by $24^{\circ} \mathrm{C}$ for $20 \mathrm{~h} / \mathrm{d}$ ); HSC, heat stress with $200 \mathrm{mg} / \mathrm{kg}$ COS supplementation. IL-1 $\beta$, interleukin-1 $\beta$; IL-6, interleukin-6; IL-10, interleukin-10; TNF- $\alpha$, tumor necrosis factor- $\alpha$.

\subsection{IL-1 $\beta, I L-6, I L-10$, and TNF- $\alpha$ in Spleen}

The effects of cyclic heat stress on IL-1 $\beta$, IL-6, IL-10, and TNF- $\alpha$ in spleen are shown in Figure 5. There was no significant difference in the level of IL-1 $\beta$ (Figure 5A) among treatments. The HS group showed increase $(p<0.05)$ in the level of IL-6 (Figure 5B) and TNF- $\alpha$ (Figure 5D), as well as decrease in the level of IL-10 (Figure 5C) compared with the CON group. The HSC group showed increase $(p<0.05)$ in the level of IL-10 compared with the HS group. 

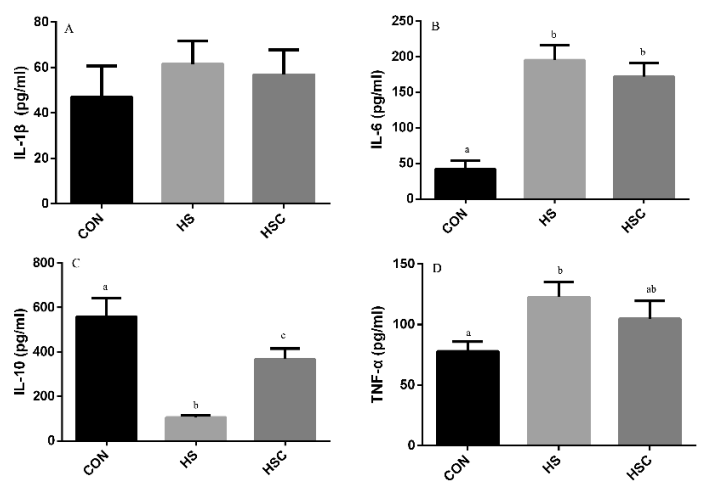

Figure 5. Effects of cycle heat stress or chitosan oligosaccharides (COS) supplementation during cyclic heat stress on IL-1 $\beta$, IL-6, IL-10, and TNF- $\alpha$ in spleen. Values are mean \pm standard error, $n=6$. The values having different superscript letters are different $(p<0.05)$. CON, thermoneutral $\left(24^{\circ} \mathrm{C}\right.$ for $\left.24 \mathrm{~h} / \mathrm{d}\right)$; HS, heat stress $\left(35^{\circ} \mathrm{C}\right.$ for $4 \mathrm{~h} / \mathrm{d}$ followed by $24^{\circ} \mathrm{C}$ for $20 \mathrm{~h} / \mathrm{d}$ ); HSC, heat stress with $200 \mathrm{mg} / \mathrm{kg}$ COS supplementation. IL-1 $\beta$, interleukin-1 $\beta$; IL-6, interleukin-6; IL-10, interleukin-10; TNF- $\alpha$, tumor necrosis factor- $\alpha$.

\subsection{IL-1 $\beta, I L-6$, IL-10, and TNF- $\alpha$ in Kidney}

The effects of cyclic heat stress on IL-1 $\beta$, IL-6, IL-10, and TNF- $\alpha$ in kidney are shown in Figure 6. There was no significant difference in the level of IL-1 $\beta$ (Figure 6A) among treatments. The HS group showed increase $(p<0.05$ ) in the level of IL-6 (Figure 6B) and TNF- $\alpha$ (Figure 6D), as well as decrease in the level of IL-10 (Figure 6C) compared with the CON group.
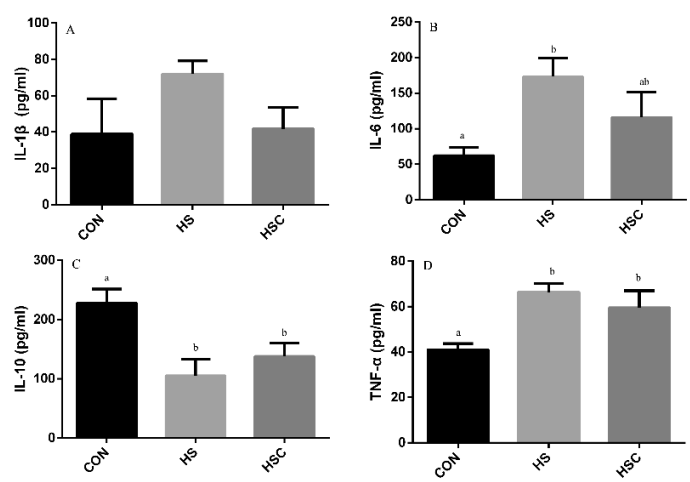

Figure 6. Effects of cycle heat stress or chitosan oligosaccharides (COS) supplementation during cyclic heat stress on IL-1 $\beta$, IL-6, IL-10, and TNF- $\alpha$ in kidney. Values are mean \pm standard error, $\mathrm{n}=6$. The values having different superscript letters are different $(p<0.05)$. CON, thermoneutral $\left(24^{\circ} \mathrm{C}\right.$ for $\left.24 \mathrm{~h} / \mathrm{d}\right) ; \mathrm{HS}$, heat stress $\left(35^{\circ} \mathrm{C}\right.$ for $4 \mathrm{~h} / \mathrm{d}$ followed by $24^{\circ} \mathrm{C}$ for $\left.20 \mathrm{~h} / \mathrm{d}\right)$; HSC, heat stress with $200 \mathrm{mg} / \mathrm{kg}$ COS supplementation. IL-1 $\beta$, interleukin-1 $\beta$; IL-6, interleukin-6; IL-10, interleukin-10; TNF- $\alpha$, tumor necrosis factor- $\alpha$.

\section{Discussion}

The current study revealed that dietary COS supplementation improved rat performance, relative weight of spleen and kidney, enhanced antioxidant capacities, and alleviated inflammatory response in rats under heat stress.

In the current study, it is clearly demonstrated that rat average daily gain (ADG) is reduced due to reduction in average daily feed intake (ADFI), which was consistent with those of Azed et al. [15] and Wang et al. [8], who reported depressed growth performance, feed intake, and feed efficiency under heat stress. Furthermore, heat-stressed rat fed COS exhibited a better ADG, which is consistent with a previous study that oligosaccharides improve growth performance in broilers under heat stress [9].

Water is an essential nutrient for animals, especially under heat stress condition. Water intake during heat stress is a limiting factor for survival and performance, due to its fundamental role in temperature regulation and maintenance of hydration balance. Water restriction enhances the 
detrimental effects of heat stress on animal performance. Under heat stress, the increasing panting and sweating increase water losses, while the water used by metabolism is reduced [45]. The current results indicated that rat drank more water under heat stress for water replenishment.

Heat stress proved to disturb the balance between the production of ROS and the antioxidant systems in animals [15,46]. MDA is the end product of lipid peroxidation, and is the indicator of lipid peroxidation. Former studies have indicated that heat stress can induce lipid peroxidation [9]. Consistently, in the current study, heat-stressed rat exhibited a higher MDA content in liver, spleen, and kidney, whereas dietary COS supplementation numerically reduces MDA content in liver, spleen, and kidney, implying that COS administration could attenuate oxidative damage by heat stress. In addition, SOD, CAT, GSH-Px, GSH, and T-AOC activities were checked to estimate the response of enzymatic and non-enzymatic antioxidant systems, respectively. Compared to the CON group, rats in HS group showed a significant decrease in CAT and GSH-Px activity in liver, a significant decrease in GSH-Px and GSH activity in spleen, and a significant decrease in SOD, GSH-Px, and T-AOC activity in kidney. However, dietary COS supplementation increased the activity of GSH-Px in liver, spleen, and kidney, as well as GSH in spleen, which may alleviate the heat-stress-induced antioxidant damage. Glutathione antioxidant system plays a pivotal role in cellular defense against ROS, GSH-Px function either directly or indirectly as antioxidants, and GSH plays an important role in scavenging reactive oxygen species [47]. It has been reported that dietary chitosan supplementation could enhance the serum SOD, CAT, and GSH-Px of diquat challenged weaning pigs [48]. In addition, dietary chitosan supplementation can prevent lipid peroxidation induced by LPS and retain GSH and CAT activity [42].

Former studies have demonstrated that heat stress significantly up-regulated the level of pro-inflammatory cytokines TNF- $\alpha$, IL-1 $\beta$, and IL-6, whereas it down-regulated anti-inflammatory cytokines IL-10 $[8,13]$. In the current study, the higher levels of IL-1 $\beta$ in liver and IL- 6 and TNF- $\alpha$ in spleen and kidney were found in the HS group compared to the CON group, while cytokine IL-10 level was lower. Meanwhile, in the liver, the lower IL-1 $\beta$ but greater IL-10 concentration was observed in the HSC group compared to the HS group, as well as greater IL-10 concentration in spleen, which indicated that COS plays a virtue role in alleviating inflammatory response. Similar to our results, previous studies indicated that dietary COS supplementation reduced pro-inflammatory cytokines IL-1 $\beta$, IL-6, and TNF- $\alpha$, as well as increased anti-inflammatory cytokine IL-10 [41,42,49].

\section{Conclusions}

Collectively, our studies indicated that dietary COS supplementation was beneficial to heat-stressed rats, protecting them from oxidative damage and alleviating the inflammatory response.

Author Contributions: All authors have checked the final version of the manuscript. R.L. and Z.Z., designed the study, study execution, sampling, data collection and analysis, and the manuscript's writing; S.L. and Q.C., contributed to carrying out the study, sampling and analyzing the laboratory metabolites, and to data collection and analysis.

Funding: The authors appreciate the financial support for this investigation by the program for scientific research start-up funds of Guangdong Ocean University (101402/R18005).

Conflicts of Interest: The authors declare that there are no conflict of interest.

\section{References}

1. Attia, Y.; Hassan, R.; Tag El-Din, A.; Abou-Shehema, B. Effect of ascorbic acid or increasing metabolizable energy level with or without supplementation of some essential amino acids on productive and physiological traits of slow-growing chicks exposed to chronic heat stress. J. Anim. Physiol. Anim. Nutr. 2011, 95, 744-755. [CrossRef] [PubMed]

2. Azad, M.; Kikusato, M.; Maekawa, T.; Shirakawa, H.; Toyomizu, M. Metabolic characteristics and oxidative damage to skeletal muscle in broiler chickens exposed to chronic heat stress. Comp. Biochem. Physiol. Part A. Mol. Integr. Physiol. 2010, 155, 401-406. [CrossRef] [PubMed] 
3. Azuma, K.; Osaki, T.; Minami, S.; Okamoto, Y. Anticancer and anti-inflammatory properties of chitin and chitosan oligosaccharides. J. Func. 2015, 6, 33-49. [CrossRef] [PubMed]

4. Chen, Z.; Xie, J.; Wang, B.; Tang, J. Effect of $\gamma$-aminobutyric acid on digestive enzymes, absorption function, and immune function of intestinal mucosa in heat-stressed chicken. Poult. Sci. 2014, 93, 2490-2500. [CrossRef]

5. Cheng, Y.; Chen, Y.; Chen, R.; Su, Y.; Zhang, R.; He, Q.; Wang, K.; Wen, C.; Zhou, Y. Dietary mannan oligosaccharide ameliorates cyclic heat stress-induced damages on intestinal oxidative status and barrier integrity of broilers. Poult. Sci. 2019, 98, 4767-4776. [CrossRef]

6. Chung, M.J.; Park, J.K.; Park, Y.I. Anti-inflammatory effects of low-molecular weight chitosan oligosaccharides in IgE-antigen complex-stimulated RBL-2H3 cells and asthma model mice. Int. Immunopharmacol. 2012, 12, 453-459. [CrossRef]

7. De Barboza, G.D.; Guizzardi, S.; de Talamoni, N.T. Molecular aspects of intestinal calcium absorption. World J. Gastroenterol. 2015, 21, 7142-7154. [CrossRef]

8. Etches, R.; John, T.; Gibbins, A.V. Behavioural, physiological, neuroendocrine and molecular responses to heat stress. In Poultry Production in Hot Climates; Daghir, N.J., Ed.; CAB International: Wallingford, UK, 2018; pp. 31-66.

9. Ganesan, S.; Summers, C.; Pearce, S.; Gabler, N.; Valentine, R.; Baumgard, L.; Rhoads, R.; Selsby, J. Short-term heat stress causes altered intracellular signaling in oxidative skeletal muscle. J. Anim. Sci. 2017, 95, 2438-2451. [CrossRef]

10. Habibian, M.; Ghazi, S.; Moeini, M.M.; Abdolmohammadi, A. Effects of dietary selenium and vitamin E on immune response and biological blood parameters of broilers reared under thermoneutral or heat stress conditions. Int. J. Biometeorol. 2014, 58, 741-752. [CrossRef]

11. Honary, S.; Maleki, M.; Karami, M. The effect of chitosan molecular weight on the properties of alginate/chitosan microparticles containing prednisolone. Trop. J. Pharmacol. Res. 2009, 8, 53-61. [CrossRef]

12. Hu, S.L.; Wang, Y.; Wen, X.L.; Wang, L.; Jiang, Z.Y.; Zheng, C.T. Effects of low-molecular-weight chitosan on the growth performance, intestinal morphology, barrier function, cytokine expression and anti-oxidant system of weaned piglets. BMC Vet. Res. 2018, 14, 215-221. [CrossRef] [PubMed]

13. Hyung, J.H.; Ahn, C.B.; Kim, B.I.; Kim, K.; Je, J.Y. Involvement of Nrf2-mediated heme oxygenase-1 expression in anti-inflammatory action of chitosan oligosaccharides through MAPK activation in murine macrophages. Eur. J. Pharmacol. 2016, 793, 43-48. [CrossRef]

14. Jeon, Y.J.; Kim, S.K. Antitumor activity of chitosan oligosaccharides produced in ultrafiltration membrane reactor system. J. Microbiol. Biotechnol. 2002, 12, 503-507.

15. Kim, J.N.; Chang, I.Y.; Kim, H.I.; Yoon, S.P. Long-term effects of chitosan oligosaccharide in streptozotocin-induced diabetic rats. Islets 2009, 1, 111-116. [CrossRef] [PubMed]

16. Lan, R.X.; Kim, I.H. Effects of feeding diets containing essential oils and betaine to heat-stressed growing-finishing pigs. Arch. Anim. Nutr. 2018, 72, 368-378. [CrossRef]

17. Lee, J.Y.; Termsarasab, U.; Lee, M.Y.; Kim, D.H.; Lee, S.Y.; Kim, J.S.; Cho, H.J.; Kim, D.D. Chemosensitizing indomethacin-conjugated chitosan oligosaccharide nanoparticles for tumor-targeted drug delivery. Acta Biomaterialia 2017, 57, 262-273. [CrossRef]

18. Lin, X.J.; Lin, C.H.; Zhao, T.B.; Zuo, D.; Ye, Z.J.; Liu, L.; Lin, M.T. Quercetin protects against heat stroke-induced myocardial injury in male rats: Antioxidative and antiinflammatory mechanisms. Chemico-Biol. Interact. 2017, 265, 47-54. [CrossRef]

19. Liu, X.L.; Xia, W.S.; Jiang, Q.X.; Yu, P.P.; Yue, L. Chitosan oligosaccharide-N-chlorokojic acid mannich base polymer as a potential antibacterial material. Carbohyd. Polym. 2018, 182, 225-234. [CrossRef]

20. Liu, X.S.; Huang, H.Y.; Liu, G.Y.; Zhou, W.B.; Chen, Y.J.; Jin, Q.; Ji, J. Multidentate zwitterionic chitosan oligosaccharide modified gold nanoparticles: Stability, biocompatibility and cell interactions. Nanoscale 2013, 5, 3982-3991. [CrossRef]

21. Min, L.; Zheng, N.; Zhao, S.; Cheng, J.; Yang, Y.; Zhang, Y.; Yang, H.; Wang, J. Long-term heat stress induces the inflammatory response in dairy cows revealed by plasma proteome analysis. Biochem. Biophysiol. Res. Comm. 2016, 471, 296-302. [CrossRef]

22. Naveed, M.; Phil, L.; Sohail, M.; Hasnat, M.; Baig, M.M.F.A.; Ihsan, A.U.; Shumzaid, M.; Kakar, M.U.; Husain, T.; Akabar, M. Chitosan oligosaccharide (COS): An overview. Int. J. Biol. Macromol. 2019, 129, 827-843. [CrossRef] [PubMed] 
23. Pinho-Ribeiro, F.A.; Hohmann, M.S.; Borghi, S.M.; Zarpelon, A.C.; Guazelli, C.F.; Manchope, M.F.; Casagrande, R.; Verri, W.A., Jr. Protective effects of the flavonoid hesperidin methyl chalcone in inflammation and pain in mice: Role of TRPV1, oxidative stress, cytokines and NF-kB. Chem. Biol. Interact. 2015, 228, 88-99. [CrossRef] [PubMed]

24. Qiao, Y.; Bai, X.F.; Du, Y.G. Chitosan oligosaccharides protect mice from LPS challenge by attenuation of inflammation and oxidative stress. Int. Immunopharmacol. 2011, 11, 121-127. [CrossRef] [PubMed]

25. Rahman, M.H.; Hjeljord, L.G.; Aam, B.B.; Sørlie, M.; Tronsmo, A. Antifungal effect of chito-oligosaccharides with different degrees of polymerization. Eur. J. Plant. Pathol. 2015, 141, 147-158. [CrossRef]

26. Rajaei-Sharifabadi, H.; Ellestad, L.; Porter, T.; Donoghue, A.; Bottje, W.G.; Dridi, S. Noni (Morinda citrifolia) modulates the hypothalamic expression of stress-and metabolic-related genes in broilers exposed to acute heat stress. Front. Genet. 2017, 8, 192. [CrossRef] [PubMed]

27. Reeves, P.G. Components of the AIN-93 diets as improvements in the AIN-76A diet. J. Nutr. 1997, 127, 838S-841S. [CrossRef]

28. Renaudeau, D.; Collin, A.; Yahav, S.; De Basilio, V.; Gourdine, J.; Collier, R.J. Adaptation to hot climate and strategies to alleviate heat stress in livestock production. Animal 2012, 6, 707-728. [CrossRef]

29. Rhoads, R.P.; Baumgard, L.H.; Suagee, J.K.; Sanders, S.R. Nutritional interventions to alleviate the negative consequences of heat stress. Adv. Nutr. 2013, 4, 267-276. [CrossRef]

30. Sahin, K.; Orhan, C.; Akdemir, F.; Tuzcu, M.; Iben, C.; Sahin, N. Resveratrol protects quail hepatocytes against heat stress: Modulation of the Nrf2 transcription factor and heat shock proteins. J. Anim. Physiol. Anim. Nutr. 2011, 96, 66-74. [CrossRef]

31. Sahin, K.; Orhan, C.; Tuzcu, Z.; Tuzcu, M.; Sahin, N. Curcumin ameloriates heat stress via inhibition of oxidative stress and modulation of Nrf2/HO-1 pathway in quail. Food. Chem. Toxicol. 2012, 50, 4035-4041. [CrossRef]

32. Sankar, P.; Telang, A.G.; Manimaran, A. Protective effect of curcumin on cypermethrin-induced oxidative stress in Wistar rats. Exp. Toxicol. Pathol. 2012, 64, 487-493. [CrossRef] [PubMed]

33. Shang, W.T.; Si, X.; Zhou, Z.K.; Wang, J.X.; Strappe, P.; Blanchard, C. Studies on the unique properties of resistant starch and chito-oligosaccharide complexes for reducing high-fat diet-induced obesity and dyslipidemia in rats. J. Funct. Foods. 2017, 38, 20-27. [CrossRef]

34. Shukla, S.; Jadaun, A.; Arora, V.; Sinha, R.K.; Biyani, N.; Jain, V. In vitro toxicity assessment of chitosan oligosaccharide coated iron oxide nanoparticles. Toxicol. Rep. 2015, 2, 27-39. [CrossRef] [PubMed]

35. Song, Z.; Cheng, K.; Zhang, L.; Wang, T. Dietary supplementation of enzymatically treated Artemisia annua could alleviate the intestinal inflammatory response in heat-stressed broilers. J. Therm. Biol. 2017, 69, 184-190. [CrossRef]

36. St-Pierre, N.; Cobanov, B.; Schnitkey, G. Economic losses from heat stress by US livestock industries. J. Dairy Sci. 2003, 86, E52-E77. [CrossRef]

37. Sun, T.; Qin, Y.Y.; Xu, H.L.; Xie, J.; Hu, D.M.; Xue, B.; Hua, X.Y. Antibacterial activities and preservative effect of chitosan oligosaccharide maillard reaction products on Penaeus vannamei. Int. J. Biol. Macromol. 2017, 105, 764-768. [CrossRef]

38. Wang, W.; Yan, F.; Hu, J.; Amen, O.; Cheng, H. Supplementation of Bacillus subtilis-based probiotic reduces heat stress-related behaviors and inflammatory response in broiler chickens. J. Anim. Sci. 2018, 96, 1654-1666. [CrossRef]

39. Wei, P.; Ma, P.; Xu, Q.S.; Bai, Q.H.; Gu, J.G.; Xi, H.; Du, Y.G.; Yu, C. Chitosan oligosaccharides suppress production of nitric oxide in lipopolysaccharide-induced N9 murine microglial cells in vitro. Glycoconjugate J. 2012, 29, 285-295. [CrossRef]

40. Wu, W.; Xiao, Z.B.; An, W.Y.; Dong, Y.Y.; Zhang, B.K. Dietary sodium butyrate improves intestinal development and function by modulating the microbial community in broilers. PLoS ONE 2018, 13, e0197762. [CrossRef]

41. Xie, C.; Long, C.; Wu, X.; Yang, H.; Fan, Z.; Xiao, D.; Wang, Y.; Yin, Y. Effect of maternal supplementation with chitosan oligosaccharide on the anti-oxidant capacity of suckling piglets. J. Anim. Sci. 2016, 94, 453-456. [CrossRef]

42. Xie, C.Y.; Wu, X.; Long, C.M.; Wang, Q.H.; Fan, Z.Y.; Li, S.M.; Yin, Y.L. Chitosan oligosaccharide affects anti-oxidant defense capacity and placental amino acids transport of sows. BMC Vet. Res. 2016, 12, 243. [CrossRef] [PubMed]

43. Xie, J.; Tang, L.; Lu, L.; Zhang, L.; Lin, X.; Liu, H.C.; Odle, J.; Luo, X. Effects of acute and chronic heat stress on plasma metabolites, hormones and oxidant status in restrictedly fed broiler breeders. Poult. Sci. 2015, 94, 1635-1644. [CrossRef] [PubMed]

44. Xu, Y.; Xing, Y.; Wang, Z.; Yan, S.; Shi, B. Pre-protective effects of dietary chitosan supplementation against oxidative stress induced by diquat in weaned piglets. Cell. Stress Chaperones 2018, 23, 703-710. [CrossRef] 
45. Yang, L.; Tan, G.Y.; Fu, Y.Q.; Feng, J.H.; Zhang, M.H. Effects of acute heat stress and subsequent stress removal on function of hepatic mitochondrial respiration, ROS production and lipid peroxidation in broiler chickens. Comp. Biochem. Physiol. Part C Toxicol. Pharmacol. 2010, 151, 204-208. [CrossRef]

46. Yousef, M.; Pichyangkura, R.; Soodvilai, S.; Chatsudthipong, V.; Muanprasat, C. Chitosan oligosaccharide as potential therapy of inflammatory bowel disease: Therapeutic efficacy and possible mechanisms of action. Pharmacol. Res. 2012, 66, 66-79. [CrossRef]

47. Yun, S.H.; Moon, Y.S.; SoHn, S.H.; Jang, I.S. Effects of cyclic heat stress or vitamin C supplementation during cyclic heat stress on HSP70, inflammatory cytokines, and the anti-oxidant defense system in Sprague Dawley rats. Exp. Anim. 2012, 61, 543-553. [CrossRef]

48. Zhang, J.; Bai, K.; Su, W.; Wang, A.; Zhang, L.; Huang, K.; Wang, T. Curcumin attenuates heat-stress-induced oxidant damage by simultaneous activation of GSH-related anti-oxidant enzymes and Nrf2-mediated phase II detoxifying enzyme systems in broiler chickens. Poult. Sci. 2018, 97, 1209-1219. [CrossRef]

49. Zhang, P.; Liu, W.Z.; Peng, Y.F.; Han, B.Q.; Yang, Y. Toll like receptor 4 (TLR4) mediates the stimulating activities of chitosan oligosaccharide on macrophages. Int. Immunopharmacol. 2014, 23, 254-261. [CrossRef]

(C) 2019 by the authors. Licensee MDPI, Basel, Switzerland. This article is an open access article distributed under the terms and conditions of the Creative Commons Attribution (CC BY) license (http://creativecommons.org/licenses/by/4.0/). 